\title{
Effects of land surface inhomogeneity on convection-permitting WRF simulations over central Europe
}

\author{
Sebastian Knist ${ }^{1,2,4} \cdot$ Klaus Goergen ${ }^{3,4}\left([) \cdot\right.$ Clemens Simmer $^{1,4}(\mathbb{C}$
}

Received: 1 August 2018 / Accepted: 5 April 2019 / Published online: 3 May 2019

(c) The Author(s) 2019

\begin{abstract}
This sensitivity study investigates the impact of the spatial scales of land use, soil moisture and orography patterns on landatmosphere exchange fluxes, domain-wide averages and meteorologic conditions in convection-permitting RCM simulations. We perform five WRF RCM simulations, each with the same $3 \mathrm{~km}$ resolution atmospheric setup but different combinations of coarsely resolved ( $12 \mathrm{~km}$ ) land use and soil type, initial soil moisture and orography for the heat-wave summer 2003 over central Europe. Our results indicate that a coarser-resolved orography significantly alters the flow over and around mountain ridges such as the Alps and impact the large-scale flow pattern. The smoothed mountain ridges result in weaker Föhn effects and in enhanced locally generated convective precipitation patterns, peaking earlier in the afternoon. In comparison, the impact of a coarser-resolved land use is smaller and mainly related to changes in the overall spatial fraction of a land use, rather than to the loss of heterogeneity of the different land use types on the scale analyzed here. Albeit, even small changes in the initial soil moisture (both spatial averages and local differences) have a higher potential to affect the overall simulation results, although this might also depend on the land surface model. Overall, effects induced by the coarsely resolved land surface properties are small compared to the differences between simulations with $3 \mathrm{~km}$ and $12 \mathrm{~km}$ grid spacings of the atmosphere.
\end{abstract}

\section{Introduction}

In numerical weather prediction and climate modeling, an increased model resolution generally improves the quality of simulations. While mean features on large spatio-temporal

Responsible Editor: A.-P. Dimri.

Sebastian Knist

sebastian.knist@gmx.de

Klaus Goergen

k.goergen@fz-juelich.de

Clemens Simmer

csimmer@uni-bonn.de

1 Institute for Geosciences and Meteorology, University of Bonn, Meckenheimer Allee 176, 53115 Bonn, Germany

2 Jülich Supercomputing Centre, Research Centre Jülich, Jülich, Germany

3 Institute of Bio- and Geosciences (IBG-3, Agrosphere), Research Centre Jülich, Wilhelm-Johnen-Straße, 52428 Jülich, Germany

4 Centre for High-Performance Scientific Computing in Terrestrial Systems, Geoverbund ABC/J, Jülich, Germany scales may be equally well-represented in coarser model resolution simulations, the added value of the higher resolution mostly emerges in the representation of mesoscale phenomena, regional-scale climate variability and daily extremes, especially for regions with complex orography, land-sea contrast and heterogeneous land use (Di Luca et al. 2012, 2013; Kotlarski et al. 2014; Torma et al. 2015; Prein et al. 2016). Largest improvements occur when processes are explicitly resolved by the finer grid spacing. Especially the step from convection-parameterized to convection-permitting resolution (grid spacings below about $4 \mathrm{~km}$ ) clearly improves the diurnal cycle, spatial distribution and intensities of precipitation (Kendon et al. 2012; Ban et al. 2014; Prein et al. 2015).

Higher resolutions better resolve the mesoscale processes in the atmosphere and more realistically represent the exchange of water and energy with the atmosphere over heterogeneous land surface including feedbacks to atmospheric processes that arise from an altered land-atmosphere coupling. Accordingly, the largest improvements of convection-permitting simulations compared to coarser resolution convection-parameterized simulations have been found over 
regions with heterogeneous land use and complex orography (Prein et al. 2015).

The impact of a more highly resolved land surface can be separated into effects of land use heterogeneity and of orography. Land use types may differ largely in albedo, roughness length, leaf area index, etc., which impact the surface radiation and energy balances and the coupling with the atmosphere via the turbulent transport of momentum, heat and water vapor. Dependent on the scale and contrast of its heterogeneity, land use patterns for instance may induce sensible heat flux patterns, that generate circulations ranging from the turbulent scale, affecting the state of the atmospheric boundary layer, up to organized mesoscale circulations similar to the land-sea breeze effect (Giorgi and Avissar 1997; Avissar and Schmidt 1998).

Many studies quantified the impact of surface heterogeneity on shallow convection using idealized large eddy simulations (LES) (Raasch and Harbusch 2001; van Heerwaarden and Guerau de Arellano 2008; Brunsell et al. 2011; GarciaCarreras et al. 2011; Wu et al. 2015). Roll- and cell-like structures create local areas of convergence associated with strong vertical upward motion, which tends to be connected to land surface discontinuities with strengths depending on the amplitude of the surface heterogeneity. Heterogeneityinduced circulations may lead to areas of higher relative humidity over warm patches with a higher potential for cloud formation (van Heerwaarden and Guerau de Arellano 2008). Huang and Margulis (2013) showed that strongly heterogeneous surfaces yield thicker and deeper shallow convective clouds. Rieck et al. (2014) report that the transition from shallow to deep convection is strongest over land surface heterogeneities of $12.8 \mathrm{~km}$ patch size.

Besides the static land surface characteristics, the dynamic soil moisture is a key variable for land-atmosphere interactions as it largely controls the flux partitioning into sensible and latent heat (Seneviratne et al. 2010). The non-linear impact of soil moisture on the flux partitioning is strongest in transition zones between wet and dry regimes. In a wet, energy-limited regime evapotranspiration is primarily limited by the state of the atmospheric boundary layer (ABL). In a dry, moisture-limited regime, the atmospheric moisture deficit cannot be entirely compensated by moisture supply from the land surface via evapotranspiration, i.e., the latent heat flux is constrained by the soil moisture content. Besides the absolute soil moisture value, also its heterogeneity influences the ABL (Patton et al. 2004; Huang and Margulis 2013) and convective precipitation (Hohenegger et al. 2009; Adler et al. 2011; Guillod et al. 2013; Taylor et al. 2013; Froidevaux et al. 2014). Thereby the influence of both land use and soil moisture related heterogeneity depends on the background wind conditions. Avissar and Schmidt (1998) found that already moderate winds reduce almost all impacts of surface heterogeneity, while Froidevaux et al. (2014) suggest positive or negative local soil moisture-precipitation feedbacks dependent on the background wind. For real case simulations with non-uniform surface heterogeneity patterns and various weather conditions, the complex feedback processes complicate the identification of systematic patterns in the atmosphere that can clearly be related to land surface patterns.

Orography strongly impacts atmospheric flow (Smith 1979); e.g., mountains force the airflow to ascend, which may initiate the formation of clouds and precipitation via upslope condensation and upstream or downstream triggering of convection. Thus, orography impacts precipitation intensity and its spatial distribution (e.g., Barros and Lettenmaier 1994), but also changes the hydrological cycle at the surface via mountain slope runoff. Many studies that have investigated the sensitivity of simulated orographic

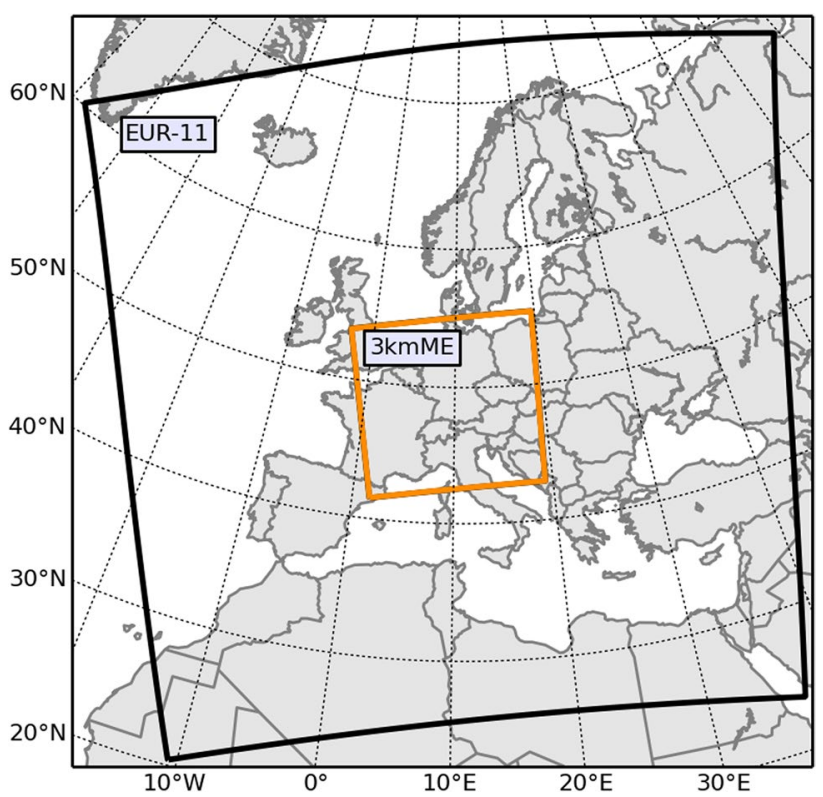

Fig. 1 Central European WRF RCM model domain (3 kmME, orange frame, $0.0275^{\circ}$ ) nested into the EURO-CORDEX domain (EUR-11, black frame, $0.11^{\circ}$ ); grids are rotated; for the analyses, the lateral boundary relaxation zone of ten grid points each is omitted

Table 1 Five setups of land surface properties used for WRF simulations at $3 \mathrm{~km}$ horizontal resolution

\begin{tabular}{lllc}
\hline & $\begin{array}{l}\text { Land use and soil } \\
\text { type }(\mathrm{km})\end{array}$ & $\begin{array}{l}\text { Initial soil mois- } \\
\text { ture }(\mathrm{km})\end{array}$ & $\begin{array}{l}\text { Orog- } \\
\text { raphy } \\
(\mathrm{km})\end{array}$ \\
\hline Setup A & 12 & 12 & 12 \\
Setup B & 12 & 12 & 3 \\
Setup C & 12 & 3 & 3 \\
Setup D & 3 & 3 & 12 \\
Setup REF & 3 & 3 & 3 \\
\hline
\end{tabular}


(a) $3 \mathrm{~km}$ : setups REF, B, C

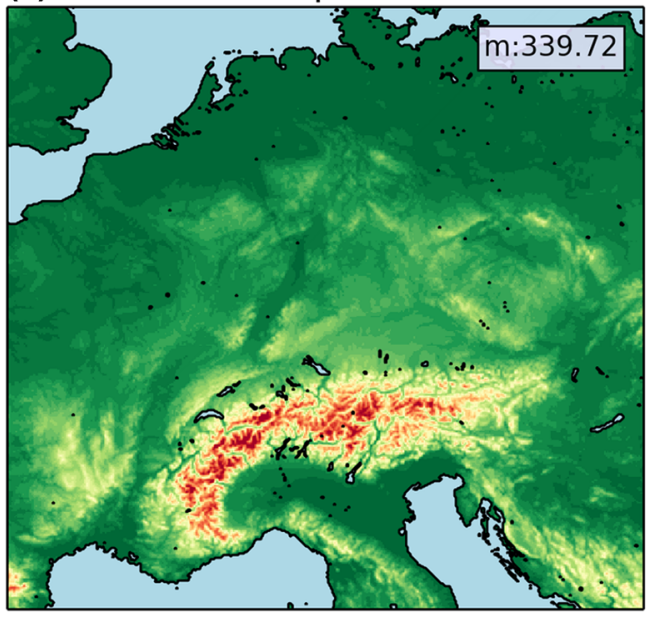

(c) $3 \mathrm{~km}$ : setups REF, D

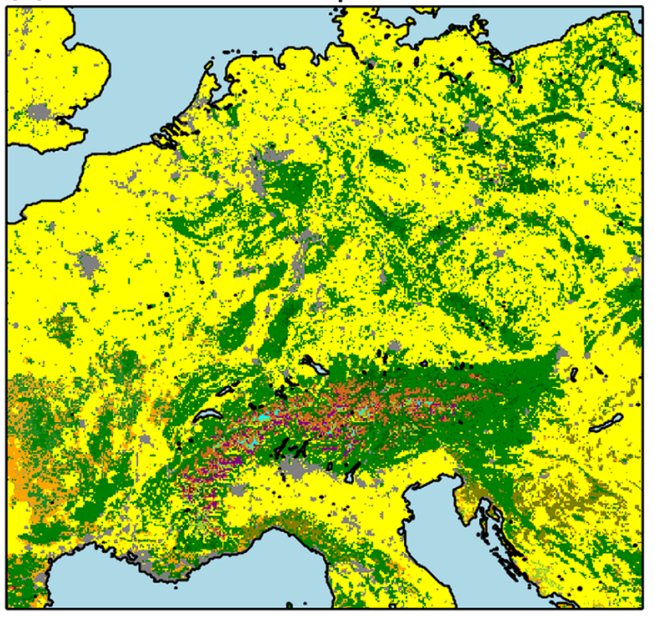

(e) $3 \mathrm{~km}$ : setups REF, C, D

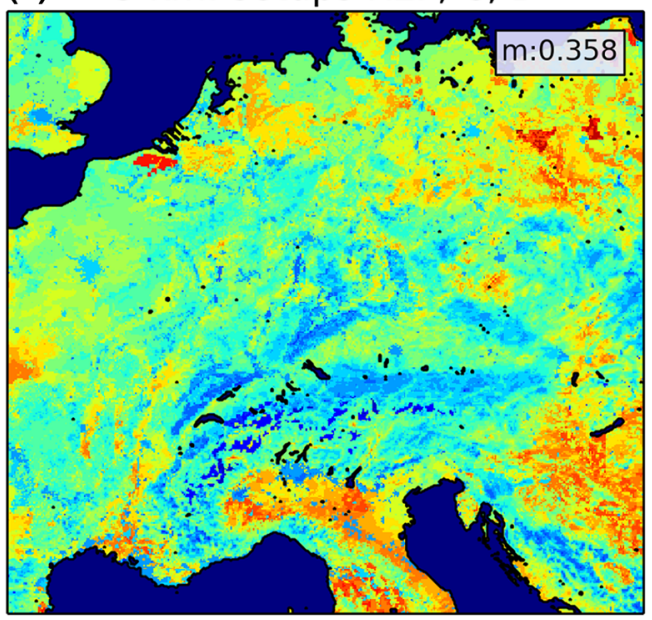

(b) $\quad 12 \mathrm{~km}$ : setups A, D

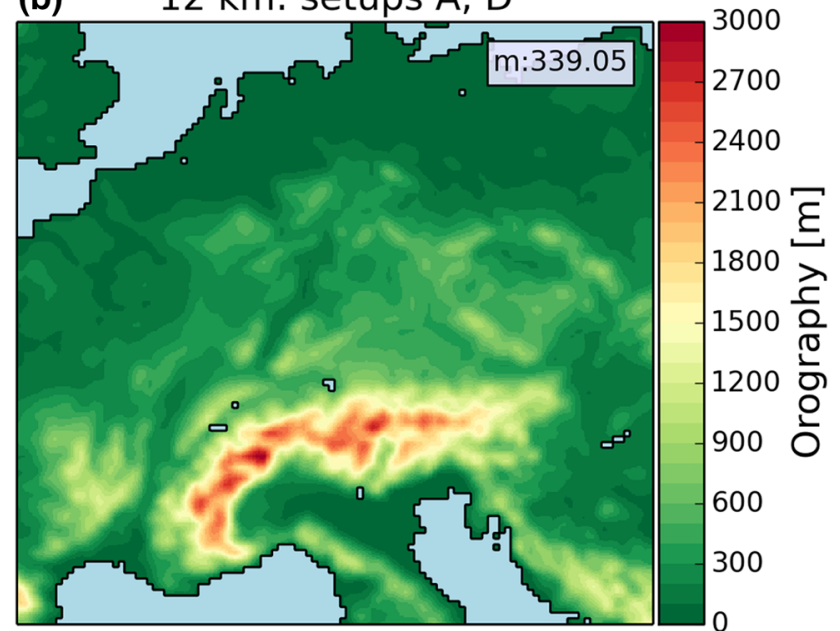

(d) $12 \mathrm{~km}$ : setups A, B, C

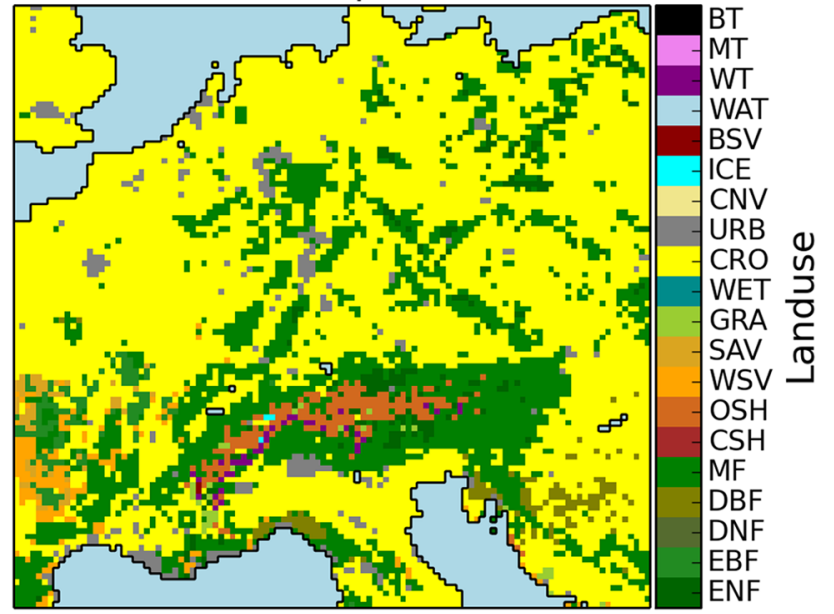

(f) $\quad 12 \mathrm{~km}$ : setups A, B

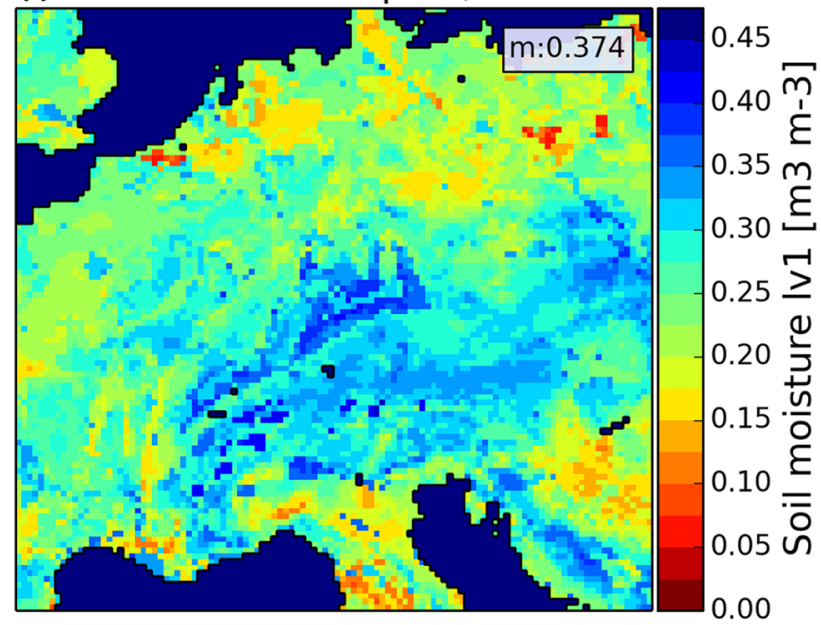

Fig. 2 Model orography (a, b), land use (c, d) and initial soil moisture $(\mathbf{e}, \mathbf{f})$ in $3 \mathrm{~km}(\mathbf{a}, \mathbf{c}, \mathbf{e})$ and $12 \mathrm{~km}$ resolution $(\mathbf{b}, \mathbf{d}, \mathbf{f})$. Dominant land use types within the model domain are ENF: evergreen needleleaf forest; $E B F$ evergreen broadleaf forest; $M F$ mixed forest; WSV wooded savanna; SAV savanna; GRA grasslands; WET wetlands; $C R O$ cropland; $U R B$ urban; ICE snow or ice; $B S V$ barely/sparsely vegetated; $W A T$ water; $W T$ wooded tundra; $M T$ mixed tundra 
precipitation to model resolution, have found that orographic precipitation generally increases with increasing grid resolution until the important orographic features are sufficiently resolved (e.g., Leung et al. 2003; Colle et al. 2005; Pedemonte et al. 2005; Richard et al. 2007; Prein et al. 2015). This improvement is to some degree attributed to the better resolution of the atmospheric processes. Smith et al. (2015) showed, however, that the simulated orographically enhanced stratiform precipitation over the UK in winter is reduced by $10 \%$ and $23 \%$, when the orography resolution is reduced from $1.5 \mathrm{~km}$ to $12 \mathrm{~km}$ and $40 \mathrm{~km}$, respectively. For mainly convective precipitation over the Alps, Prein et al. (2013) identified, just small differences in the mean precipitation diurnal cycle between convection-permitting simulations with $3 \mathrm{~km}$ and $12 \mathrm{~km}$ orography.

From the above studies, no clear conclusions on the quantitative effects of the different types of land surface heterogeneity on atmospheric motion in a non-idealized study could be drawn. Thus, we attempt in this case study to systematically investigate the impact of the spatial scales of the patterns of land use, soil moisture and orography on convection-permitting RCM simulations on land-atmosphere exchange fluxes and patterns in atmospheric state and flux variables as well as domain wide averages. To this goal, we analyze five $3 \mathrm{~km}$ grid size, convection-permitting seasonal simulations for central Europe, which were performed with different combinations of coarser $(12 \mathrm{~km})$ resolved land surface property types and allow to assess the impact of each land surface property on atmospheric processes, also in comparison to the driving $12 \mathrm{~km}$ simulation with parametrized convection. To our knowledge, such an analysis for central Europe and a full season does not yet exist.

In Sect. 2, we introduce the setup of the five WRF RCM simulations. In Sect. 3, the results are compared for several variables, first with a focus on seasonal means and similarities in the differences of spatial patterns, and second for their temporal evolution. Results are summarized and discussed in Sect. 4.

\section{RCM simulation experimental setup}

This study is based on convection-permitting regional climate simulations using the non-hydrostatic Weather Research and Forecasting model (WRF, v.3.6.1) (Skamarock et al. 2008) in a one-way double-nesting setup (see Fig. 1). The central European domain with a $0.0275^{\circ}(\sim 3 \mathrm{~km})$ grid spacing ( $3 \mathrm{kmME}, 480 \times 456$ grid points) is nested into the pan-European $0.11^{\circ}(\sim 12 \mathrm{~km})$ EURO-CORDEX domain (EUR-11, 448x436 grid points) with 50 vertical levels up to $20 \mathrm{hPa}$. For both domains the same model settings and parametrizations are used, except for the Grell-Freitas convection scheme (Grell and Dévényi 2002) used in the EUR-11
Fig. 4 Spatial distribution of upper-level soil moisture (JJA mean, first row) and its temporal evolution (15-daily means, second-last row) in the REF simulation (first column) and in the setups A-D (second-fifth column) displayed as difference to REF. Domain averages and differences are shown in the upper right corner

domain and switched off in the $3 \mathrm{kmME}$ domain. Both use WSM-5 microphysics (Hong et al. 2004), the RRTMG radiation scheme (Iacono et al. 2008), the YSU PBL scheme (Hong et al. 2006) and the NOAH land surface model (LSM) (Ek et al. 2003).

Five simulations at $3 \mathrm{~km}$ grid size have been carried out each with the same parametrization setup and identical initial conditions of the atmosphere. The $3 \mathrm{~km}$ simulations only differ from each other in the respective resolution (either $12 \mathrm{~km}$ or $3 \mathrm{~km}$ ) of the land surface characteristics (a) land use and soil type, (b) initial soil moisture, and (c) orography. See Table 1 for an overview of how the surface characteristics have been changed and Fig. 2 for the differences in the spatial distribution of the static fields.

Since the soil type classification base data have a coarser than $3 \mathrm{~km}$ resolution, no additional simulations with $12 \mathrm{~km}$ soil type and, e.g., $3 \mathrm{~km}$ land use have been carried out. Soil type is varied together with the land use.

The setup of the driving EUR-11 simulation is identical for all five simulations, and since there is no feedback from the inner 3kmME to the EUR-11 domain (1-way nesting), identical lateral boundary conditions are provided for the $3 \mathrm{kmME}$ domain for each of the five simulations. Thus,

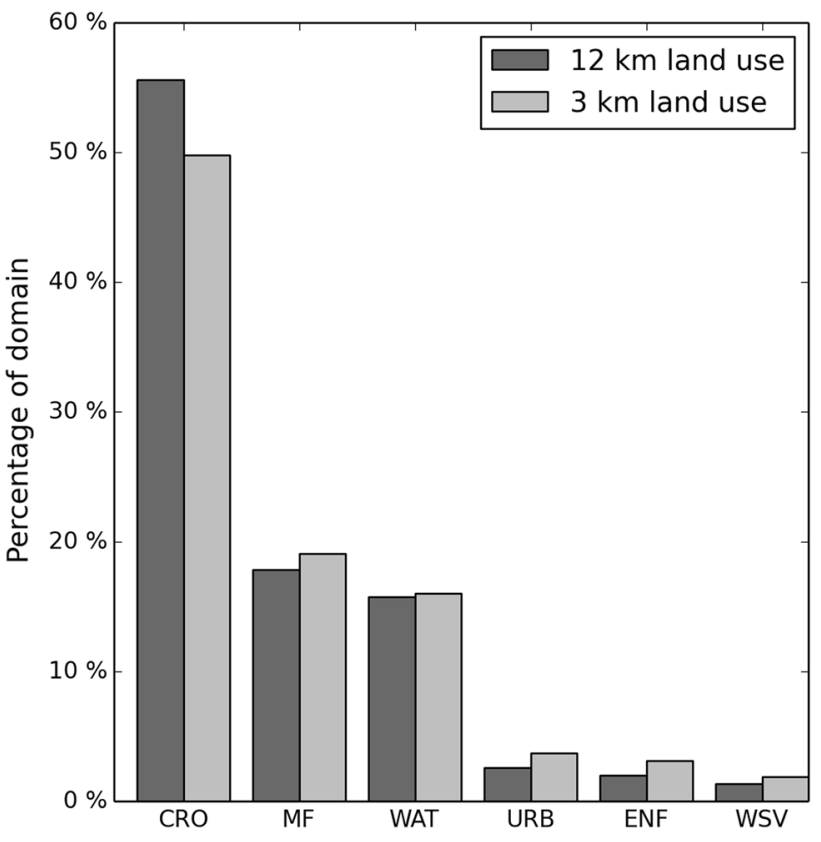

Fig. 3 Percentage of the most frequent land use types within the central European model domain in $3 \mathrm{~km}$ and $12 \mathrm{~km}$ resolution 

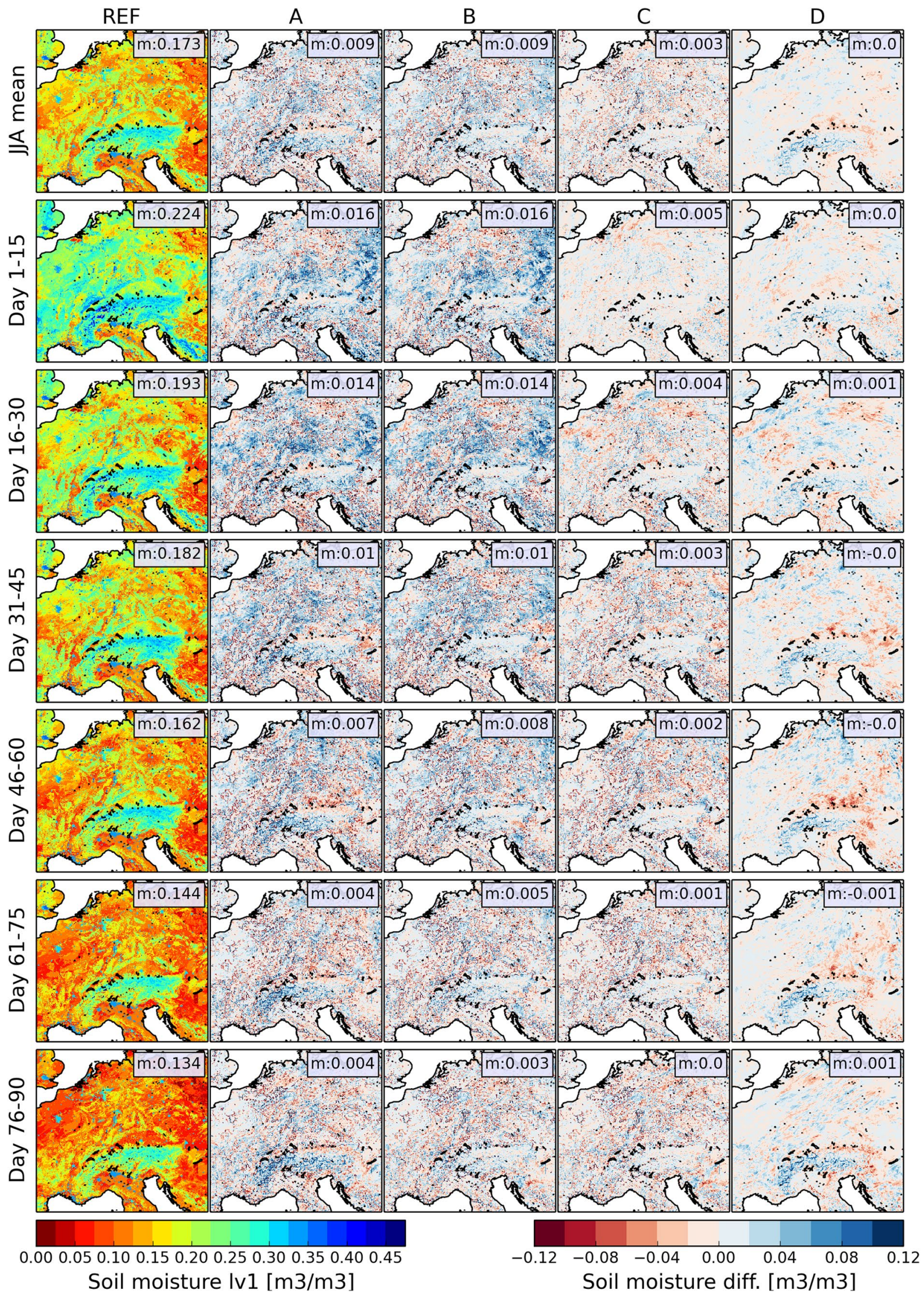
differences in the individual runs only result from the differently resolved land surface properties. Lateral boundary forcing data for the EUR-11 domain simulations are provided by 6-hourly ERA-Interim reanalysis data at $0.75^{\circ}$ grid resolution.

The experiment encompasses the summer months June, July, August (JJA) in the year 2003 as this season was characterized by strong land-atmosphere coupling conditions (Fischer et al. 2007). It had mainly convective precipitation events in June and July as well as longer dry and hot periods in July peaking in a severe heat wave in the first half of August.

The land use data are based on IGBP-MODIS data for all simulations but interpolated either to $3 \mathrm{~km}$ or $12 \mathrm{~km}$ resolution. As all setups use the same $3 \mathrm{~km}$ model grid, the coarse $12 \mathrm{~km}$ pattern of the land surface properties is generated by nearest neighbor resampling from the $12 \mathrm{~km}$ grid of the parent EUR-11 simulation. Thus, for setups A, B and $C$ the land use and soil types of $4 \times 43 \mathrm{~km}$-wide grid boxes are identical (see Fig. 2d). Accordingly, the percentages of individual land use types slightly change between the $3 \mathrm{~km}$ and $12 \mathrm{~km}$ resolutions (Fig. 3). The LSM used in our simulations does not use a mosaic approach but the dominant land use type of one grid box; thus subgrid-scale heterogeneity is ignored. The coarsely resolved orography setup for A and D is generated by a weighted bilinear interpolation from an orography resolved at $12 \mathrm{~km}$; to avoid very steep slopes between the neighboring grid cells, which would generate unrealistic wind patterns.

All simulations have been initialized with interpolated atmospheric state variables from ERA-Interim at $1^{\text {st }}$ of June 2003. To reduce the spin-up time for the soil variables (soil temperature and moisture) their initial values are taken from previous long-term WRF climate simulations started in 2001 with the same EUR-11/3kmME nesting setup; for an in depth information on these simulations, the reader if referred to Knist et al. (2018). For setups A and B the initial soil variables are taken from the $12 \mathrm{~km}$ resolved EUR-11 climate simulation and for setups $\mathrm{C}, \mathrm{D}$ and REF from the $3 \mathrm{kmME}$ climate simulations. The mean soil moisture values are slightly different between the EUR-11 and 3kmME climate simulation used for the initialization, mainly because of precipitation differences; overall the $3 \mathrm{kmME}$ climate simulations are slightly drier than the EUR-11 climate simulations. For that reason, an additional setup $C$ that uses $12 \mathrm{~km}$ land use and soil type (like setup B) is initialized with $3 \mathrm{~km}$ soil moisture from the former $3 \mathrm{kmME}$ climate simulation from Knist et al. (2018).
Fig. 5 Spatial distribution of latent heat flux (JJA mean, first row) and its temporal evolution (15-daily means, second-last row) in the REF simulation (first column) and in the individual setups A-D (secondfifth column) as difference to REF. Domain averages are shown in the upper right corner

\section{Surface properties impact on the evolution of atmospheric states}

We first analyze the mean differences of variables between the reference run REF with all land surface characteristics resolved at $3 \mathrm{~km}$, and the results of setups with all (A) or part (B-D) of the land surface properties resolved at $12 \mathrm{~km}$. As there are at least two setups that have one land surface property in coarse resolution $(12 \mathrm{~km})$ in common, similarities in the difference patterns of these setups with reference to the REF run allows to separate the impacts of the individual land surface characteristics. The REF run is used as the reference in this sensitivity study for the other setups, which have at least one land surface property at a coarse resolution; thus it is not to be seen as the truth which could only be provided by observations or-to some degree-by assimilating the observations into the simulations.

We investigate also the temporal evolution of the difference patterns between the individual setups for several variables using 15-day averages. That analysis is based on the hypothesis, that some difference patterns may depend on specific weather conditions and the large-scale synoptic conditions during JJA 2003, and that similarities in the difference patterns may remain consistent throughout the simulated time period despite different synoptic conditions.

\subsection{Latent and sensible heat fluxes}

Summer 2003 in central Europe was anomalously warm and dry and culminated in a severe heat wave beginning of August (e.g., Fischer et al. 2007). The domain spatial mean soil moisture impacting on flux partitioning between the latent and sensible heat flux continuously decreases in the reference simulation from $0.23 \mathrm{~m}^{3} / \mathrm{m}^{3}$ beginning of June to $0.13 \mathrm{~m}^{3} / \mathrm{m}^{3}$ end of August (Fig. 4, leftmost column).

While the latent heat flux dominates the turbulent fluxes in June, the system undergoes a transition from energylimited to soil moisture-limited conditions accompanied with a strong decrease of latent heat flux and an increase in sensible heat flux until the end of August (Figs. 5 and 6, leftmost column). The spatial patterns of latent and sensible heat flux are very heterogeneous due to their dependence on soil moisture, land use, and soil type. Urban areas are, e.g., clearly identified by high sensible heat fluxes and very low latent heat fluxes. High latent heat fluxes and low sensible heat fluxes are also simulated for the forested areas in the 

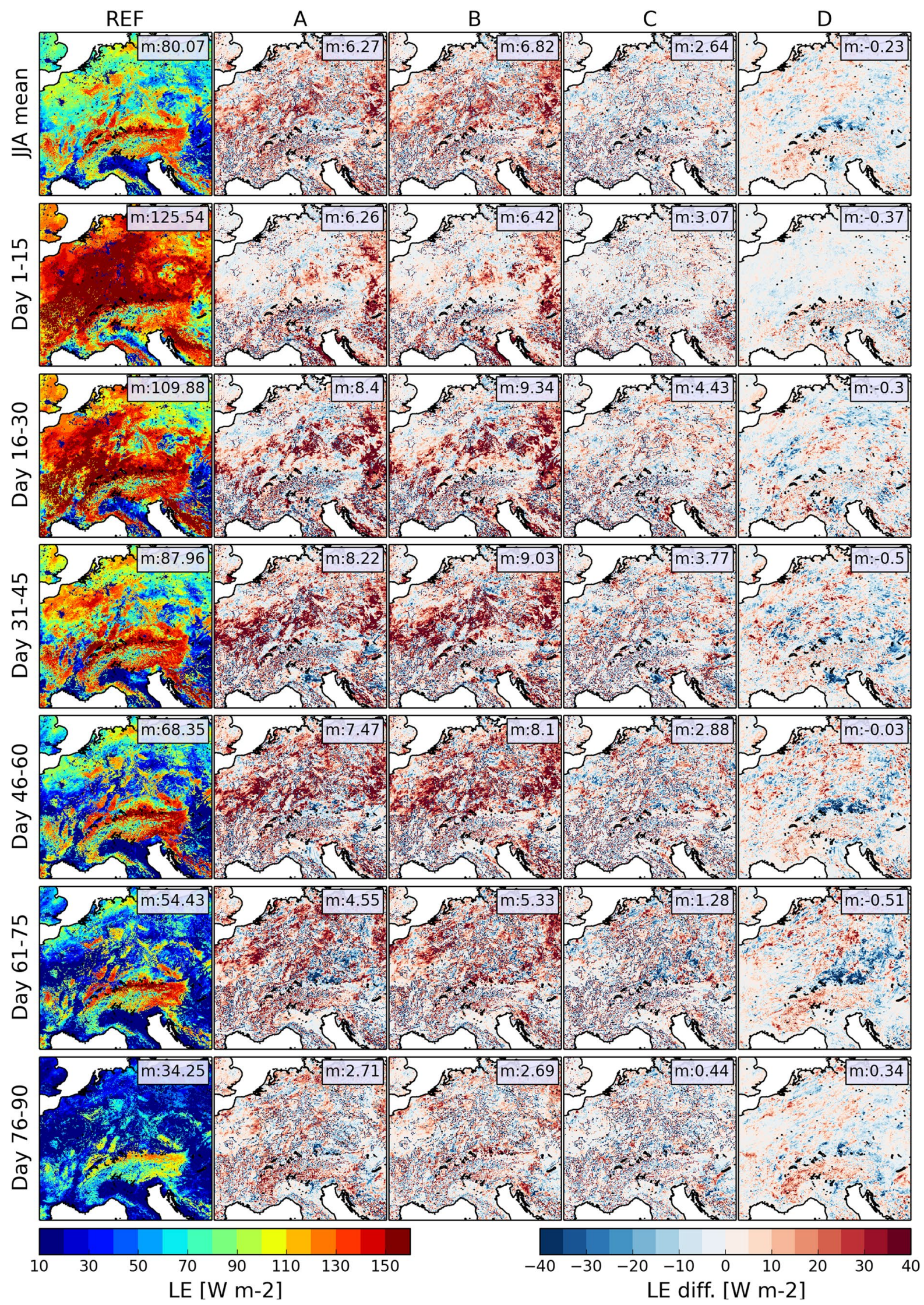

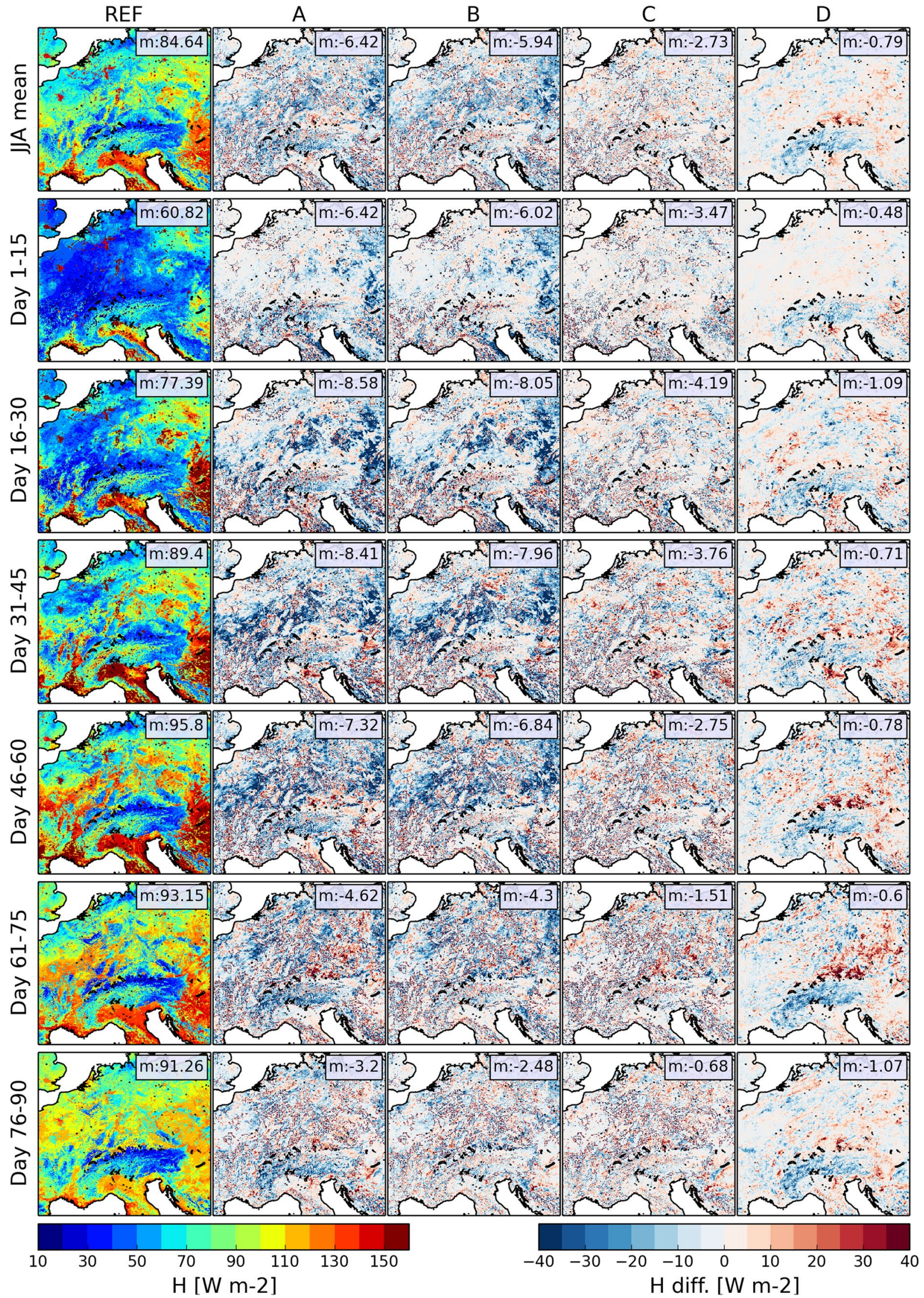
4Fig. 6 Spatial distribution of sensible heat flux (JJA mean, first row) and its temporal evolution (15-daily means, second-last row) in the REF simulation (first column) and in the individual setups A-D (second-fifth column) as difference to REF. Domain averages are shown in the upper right corner

German uplands and central France as well as in the Alpine foothills. For the lower-mostly cropland-areas, sensible heat fluxes exceed latent heat fluxes, especially in the Po valley in northern Italy and the southern parts of the domain. Soil moisture-limited conditions are reached much faster in areas with crop land use type while forested areas with their larger rooting depth and thus access to deeper soil moisture reservoirs in the Noah LSM can sustain a high evaporative fraction until August.

Different temporal turbulent flux evolutions between the reference and the different land surface characteristics setups occur instantly for coarse land use simulations (setups A, B and C) at grid points that changed their land use type with respect to the original $3 \mathrm{~km}$ reference run (Fig. 5 and 6, second row). Besides the noisy pattern with alternating positive and negative differences on the local scale, the setups A and B simulate for large areas higher mean latent and lower mean sensible heat fluxes. These differences relate to the slightly wetter initial soil moisture conditions of the $12 \mathrm{~km}$ resolution (Fig. 4), which lead to $5.4 \mathrm{~W} / \mathrm{m}^{2}$ higher (4.1 W/ $\mathrm{m}^{2}$ lower) domain average latent (sensible) heat fluxes. Interestingly, the excess in latent (and deficit in sensible heat) fluxes in setups A and B peak in mid July and not in June when the soil moisture difference is largest. This results from the non-linear relationship between soil moisture and latent heat flux: the transition from the energy-limited state (when soil moisture does not impact evapotranspiration) to the soil moisture-limited state (when evapotranspiration decreases with decreasing soil moisture) is reached earlier in the initially drier REF simulation than in the initially moister A and B setups. Until the end of August differences decrease as the latent heat flux is low in all simulations.

For setup $\mathrm{C}$ with an initial soil moisture identical to REF, strong differences mainly occur just for grid points with disparate land use types caused by the coarser resolution of the land use type maps. The domain-averaged latent heat flux for setup $\mathrm{C}$ is consistently lower than for setups $\mathrm{A}$ and $\mathrm{B}$, but $3-4 \mathrm{~W} / \mathrm{m}^{2}$ higher compared to the REF run because of the slightly different percentages of land use types (see Figs. 3 and 5).

The individual land use type contributions to the mean latent heat flux difference between REF and setup $\mathrm{C}$ are illustrated in Fig. 7, which shows time series of daily latent heat flux differences averaged over groups of grid points that undergo land use changes from REF to setup C. Accordingly, the initially higher domain average latent heat flux in setup $\mathrm{C}$ mainly results from the increase of the number of grid points with land use type crop in setup $C$ that are urban (low evapotranspiration) in REF. A similar effect holds for land use changes from mixed forest in REF to crop in setup C, and vice versa: in June crop grid points typically evapotranspirate more than mixed forest land use grid points, which reverses with the drying of the soil conditions in July and August. The slightly different fluxes between setup $\mathrm{C}$ and REF even for the same land use types at the beginning of the simulation relate to differences in mean vegetation fraction between the $3 \mathrm{~km}$ and $12 \mathrm{~km}$ resolution setups.

For setup D (like REF but coarse orography) initially only small differences compared to REF occur (Figs. 5 and $6)$. The evolving noisy latent and sensible heat flux difference patterns are mainly related to different soil moisture evolutions as a result of the differently evolving precipitation (see below). Overall, the differences in turbulent fluxes of all setups compared to REF are primarily related to the
Fig. 7 Time series of spatially averaged daily mean latent heat flux differences between setup $\mathrm{C}$ and REF for different groups of land use types that undergo a land use change from REF $(3 \mathrm{~km})$ to setup $\mathrm{C}(12 \mathrm{~km})$. The spatial averages are multiplied by the percentage of grid points of each group so that their individual contribution to the whole domain average difference (black line) is shown

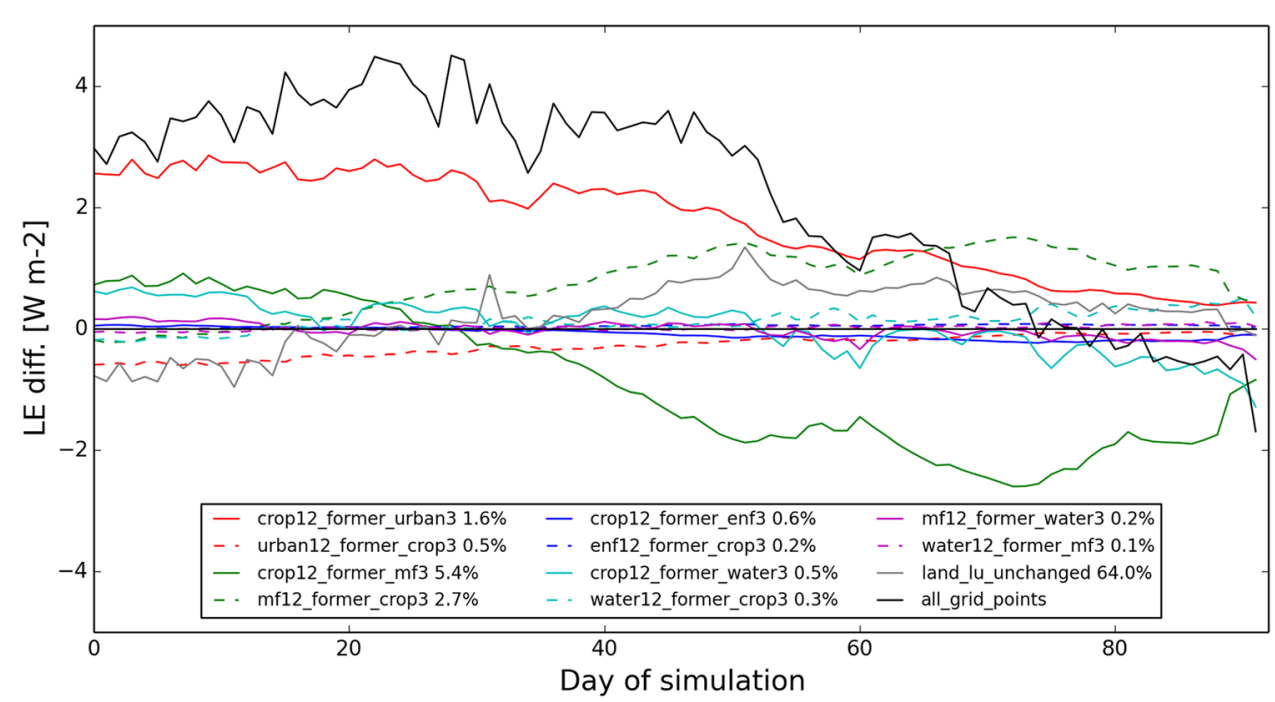



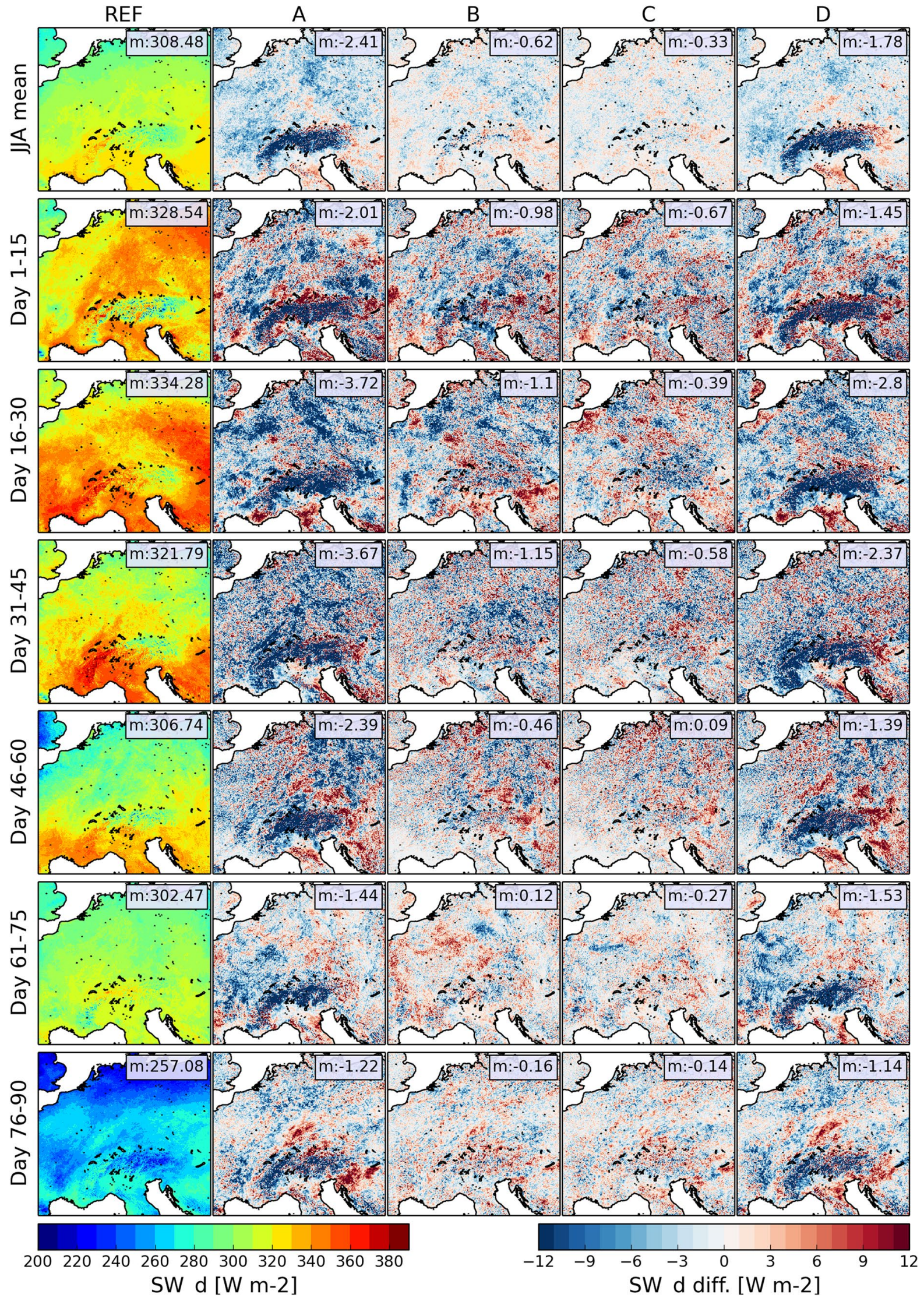
4 Fig. 8 Spatial distribution of incoming shortwave radiation (JJA mean, first row) and its temporal evolution (15-daily means, secondlast row) in the REF simulation (first column) and in the individual setups A-D (second-fifth column) as difference to REF. Domain averages are shown in the upper right corner

flux partitioning at the surface and less to differences in the incoming solar radiation, and hence cloudiness, which is discussed in the next section.

\subsection{Shortwave radiation}

Incoming shortwave radiation (SW_d) controls the variability of surface net radiation, which is the main driver of the turbulent fluxes. Accordingly, SW_d is inversely related to daytime cloudiness. Since there is no direct dependency of SW_d on land surface properties, differences in SW_d between the setups (Fig. 8) are smaller compared to the turbulent fluxes (Figs. 5 and 6). Due to the complex and non-linear land-atmosphere feedback processes, systematic difference patterns are difficult to identify not only due to the random-like internal variability evolving during the time integrations of the RCM. Nevertheless, some similarities are noticeable for the different surface characteristics setups.

The largest similarity in the difference patterns-also in terms of spatial correlation (Table 2) - is observed for the setups with the same coarse orography (A and D). Similar to the temporal evolution of the area-mean values, less shortwave radiation reaches the surface over the Alpine ridge because of the consistently higher convective activity and hence cloudiness (data not shown). Other regional patterns only sporadically occur, indicating most likely a dependency on weather conditions.

Setups B and C, which differ from REF by their coarse land use type resolution, show only scattered differences in incoming solar radiation, which mostly cancel each other in the mean. Setup B, which additionally differs from REF by an initially slightly wetter soil, generates somewhat less incoming overall shortwave radiation, due to more cloudiness (data not shown). We see very similar differences between both setups with coarse orography but different initial soil moisture, A and D. These differences most likely result from the overall higher evapotranspiration and thus more clouds in the moister setups A (and B). This causality is corroborated by the anti-correlated temporal evolution of the difference in average shortwave radiation and latent heat flux except for setup D, which suggests that in that case, the differences are dominated by different flow pattern due to the coarse orography. The difference patterns for setups B and $\mathrm{C}$ show, despite the noisy structure, some similarities on the regional scale (average daily correlation 0.49 ), that suggest a systematic impact of the coarsely resolved land use. For setups that have only one surface property in common, the highest spatial correlation exists between setup A and D (same $12 \mathrm{~km}$ orography) while the lowest correlation between setups that differ by only one surface property is found for setup A and B, i.e., different orography (Table 2).

\subsection{Precipitation}

Precipitation in the JJA 2003 simulations is characterized by high amounts in the central and eastern Alps and in the central German uplands (Fig. 9, left column). The noisy pattern with large variability on the local scale results from single convective events, whose tracks also cause lines of high precipitation amounts as seen, for example, in northern Germany-oriented WSW-ENE.

Since the location of single convective cells and its evolution is mostly random also the difference pattern of the individual setup runs with respect to the REF simulation shows large variability on the local scale. However, there are some similarities in the difference patterns on the regional scale and between the mean values over the whole domain. Consistent with the results for incoming shortwave radiation, we observe more precipitation in the setups with less shortwave radiation (more clouds). For example, setups A and D with the coarse orography are consistently wetter over the Alpine ridge where up to $30 \%$ more precipitation is simulated. Difference patterns in other regions are more heterogeneous and vary with time, while some similarities exist between the setups with coarsely resolved land surface properties. Similar to shortwave radiation, setups $\mathrm{A}$ and $\mathrm{D}$ are correlated highest (0.61) followed by setups B and C (0.48) (Table 2). Again, positive and negative differences mostly cancel each

Table 2 Mean spatial correlation between different setups' daily difference patterns to the REF simulation for shortwave radiation (SW_d) and precipitation

\begin{tabular}{llllllcc}
\hline & B vs. D & C vs. D & A vs. C & A vs. B & B vs. C & A vs. D & A vs. (B+D) \\
\hline Identical & - & sm3 & lu12 & lu12, sm12 & lu12, or3 & or12 & $\begin{array}{c}\text { lu12,sm12, } \\
\text { or12 }\end{array}$ \\
SW_d & 0.29 & 0.30 & 0.34 & 0.40 & 0.49 & 0.69 & 0.70 \\
Precip & 0.36 & 0.37 & 0.37 & 0.39 & 0.48 & 0.61 & 0.62 \\
\hline
\end{tabular}

The second row gives an indication, which surface properties are identical between the setups compared

sm soil moisture, lu land use, or orography; the numbers indicate the resolution, 3 or $12 \mathrm{~km}$ 

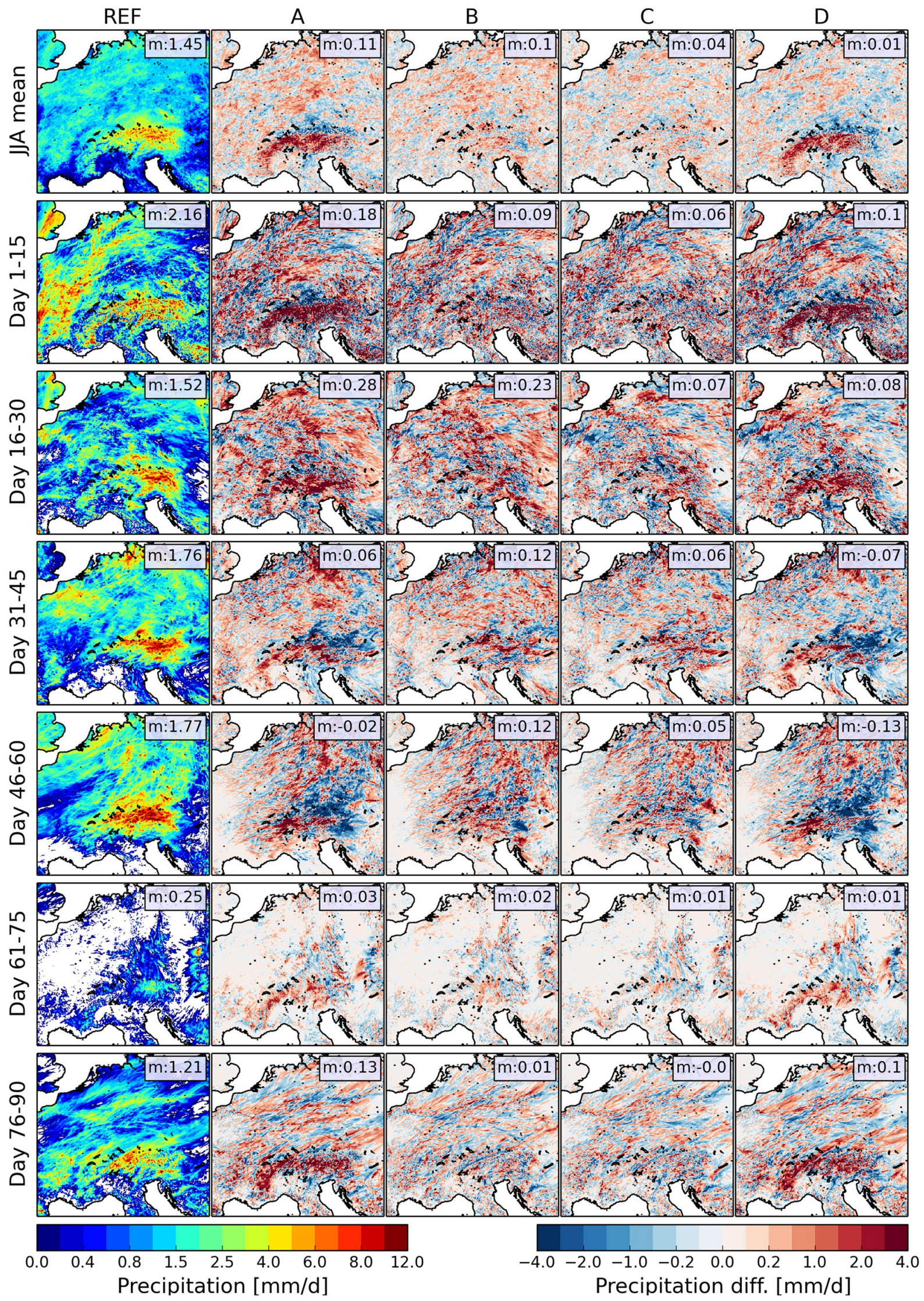
4Fig. 9 Spatial distribution of precipitation (JJA mean, first row) and its temporal evolution (15-daily sums, second-last row) in the REF simulation (first column) and in the individual setups A-D (secondfifth column) as difference to REF. Domain averages are shown in the upper right corner

other and lead to overall precipitation differences $<10 \%$ with the higher initial soil moistures leading to higher precipitation for all 15-day-averaged domain averages. Setups A and $\mathrm{B}$ (coarse land use and higher initial soil moisture) lead to about $7 \%$ more mean precipitation compared to their counterparts D and REF, respectively, with the same orographic resolution. Setups $\mathrm{C}$ and REF, which only differ in the resolution of land use and soil type, are very similar with $3 \%$ higher mean precipitation in REF (higher resolved land use distribution compared to setup D).

\subsection{CAPE and $850 \mathrm{hPa}$ level patterns}

Summer precipitation is mostly convective; thus, the precipitation response should be related to changes in the convective available potential energy (CAPE, Fig. 10a-e). High CAPE not necessarily results in stronger precipitation on average, but indicates the potential for strong convective events. The runs with coarse land use (setups A, B and C) show slightly higher overall CAPE, while the runs with coarse orography (setups A and D) simulate lower CAPE compared to their respective counterparts (setup B and REF). Moreover, the coarse orography runs (setups $A$ and D) result in consistently lower CAPE south of the Alps, which we relate to different flow patterns (see below) over and around the Alpine ridge with a smoother orography.

The coarsely resolved orography (setups A and D) influences the flow pattern in $850 \mathrm{hPa}$ over the whole period much stronger than in the highly resolved setups $B$ and $C$ (Fig. 10f-j). The strongest differences occur south of the Alps. On any occurrence of north-westerly flows towards the Alps (which is the case for most of the simulated period, Fig. 10f), lee cyclogenesis results in lower surface pressure and the $850 \mathrm{hPa}$ geopotential height, which is, however, weaker in the coarse orography setups A and D (Fig. 10g, j). A possible reason is the overall lower height of the main Alpine ridge in the smoothed $12 \mathrm{~km}$ orography, which leads to a weaker Föhn effect resulting in slightly lower temperatures at the downwind side and less precipitation at the windward side of the mountains (Fig. 101 and o). The rest of the domain does not exhibit significant differences in geopotential and flow pattern between the individual setups. Runs with coarsely resolved land use but highly resolved orography (setups B and C) do not differ much in mean $850 \mathrm{hPa}$ geopotential height compared to REF, thus orography dominates the observed changes in the flow pattern.
In general, all strong local temperature differences between setups with coarse and fine resolved land use vanish above the boundary layer and no significant effect of land use heterogeneity is seen at $850 \mathrm{hPa}$ (Fig. 10k-o). The overall slightly colder $850 \mathrm{hPa}$ mean temperature $(0.1-0.5 \mathrm{~K})$ in setups A and B are likely related to the overall higher latent heat flux and more evaporative cooling due to slightly wetter initial soil in those setups (see Fig. 5 and 6). This is consistent with difference patterns of $850 \mathrm{hPa}$ specific humidity that is slightly higher in setups A and B compared to REF (Fig. 10p-t). Again, the strong heterogeneity at the surface completely vanishes at the $850 \mathrm{hPa}$ level.

\subsection{Mean diurnal cycle of orographic precipitation}

Besides the larger scale difference pattern caused by the altered flow pattern, the coarsely resolved orography also leads to overall more precipitation and clouds especially over the Alps. The mostly convective summer precipitation follows a pronounced mean diurnal cycle with maximum precipitation in the afternoon. While nighttime precipitation amounts are quite similar, the coarse orography runs simulate higher $(+40 \%)$ and earlier $(-1 \mathrm{~h})$ afternoon maxima compared to REF (Fig. 11). The mean hourly precipitation patterns suggest that the coarse orography facilitates the initiation and evolution of more organized, longer lasting, and larger convective cells. The higher convective activity is consistent with the higher mean CAPE values reached in these runs (see Fig. 10a-e).

\section{Discussion and conclusion}

Five WRF simulations each with the same atmospheric setup at $3 \mathrm{~km}$ resolution but different combinations of coarsely resolved $(12 \mathrm{~km})$ land use and soil type, initial soil moisture, and orography have been performed for JJA 2003. Our results indicate that a coarser-resolved orography significantly alters the flow over and around extensive mountain ridges such as the Alps and hence impacts the large-scale flow pattern. This could be a so far undiscovered added value of convection-permitting simulations on the lee side of the western Alps, that could improve the simulated climate in this region, especially the Po valley, which is known to be error-prone in climate simulations (Nikulin et al. 2011; Kotlarski et al. 2014; Prein et al. 2016). The coarser resolution leads to weaker Föhn effects and might also influence lee cyclogenesis, which could be investigated in future studies with a larger domain that would also have to cover larger parts of the northern Mediterranean Sea.

The smoothed orography furthermore results in enhanced locally generated convective precipitation patterns peaking 


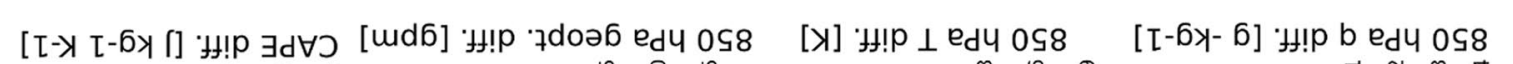
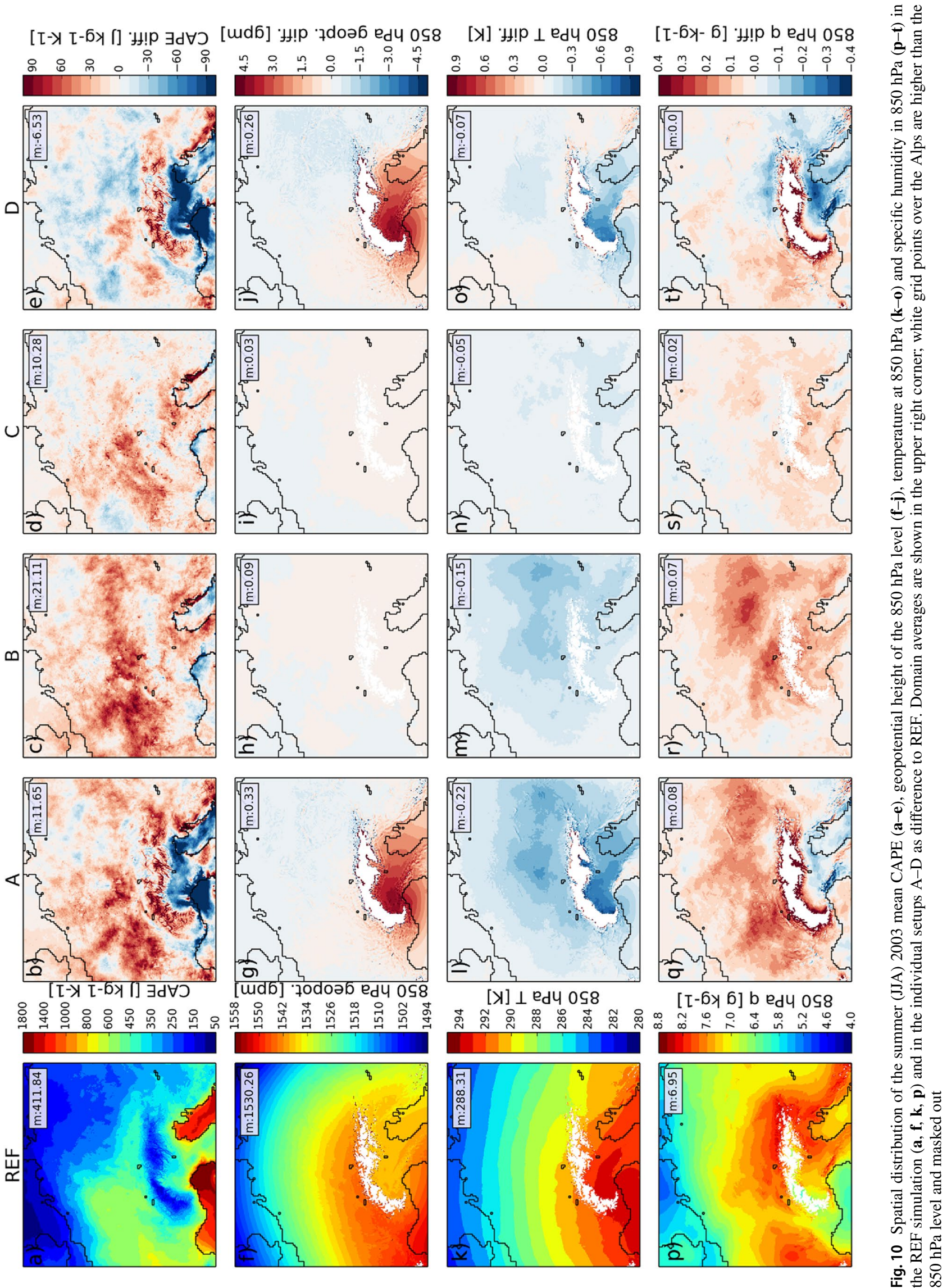

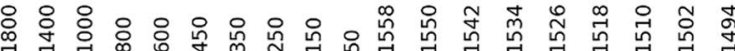
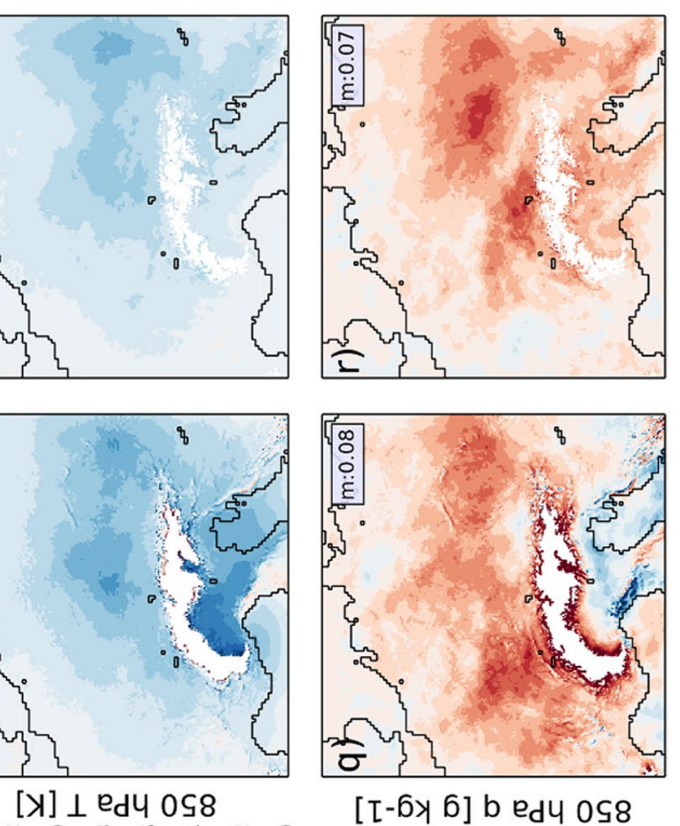

[ $[-6 \times$ 6] b edy 0s8
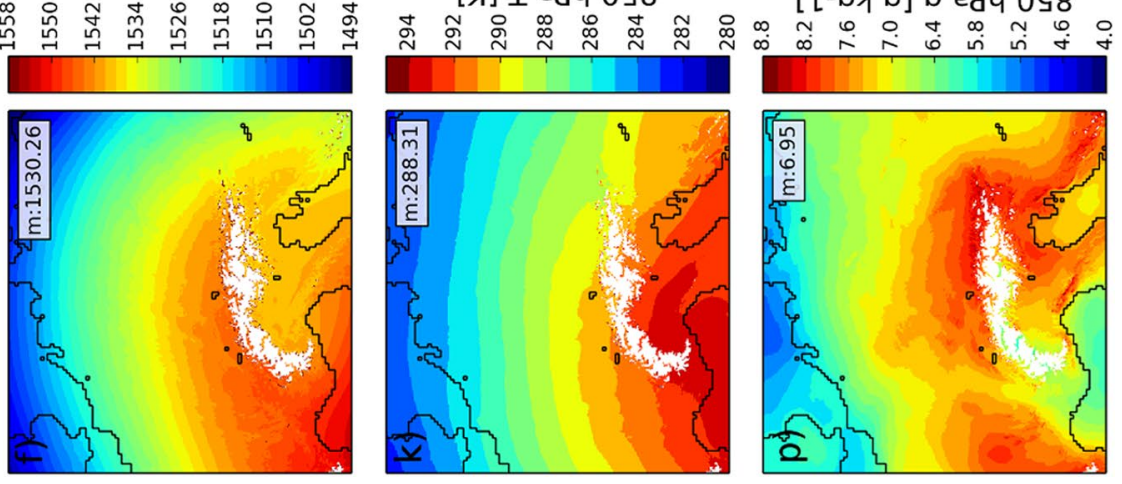

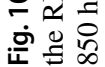


earlier in the afternoon. This is at variance with other studies, which suggest lower precipitation over smoothed orography (e.g. Smith et al. 2015). These seemingly conflicting results can likely be attributed to the character of precipitation, which was mostly convective in our summer 2003 study and predominantly stratiform in the winter cases analyzed in Smith et al. (2015). Also, Prein et al. (2013) identified only small differences in simulated convective summer precipitation over the eastern Alpine region between $3 \mathrm{~km}$ and $12 \mathrm{~km}$ orography runs. They concluded that the typically positive precipitation bias in convection-parameterized simulations mainly results from the parameterization scheme and the less resolved atmospheric dynamics rather than from the coarsely resolved orography. Our study does not confirm this conclusion. The mean diurnal cycle of precipitation over the Alpine region in the setups REF and D and in the driving EUR-11 simulation (Fig. 11) suggests that the much higher precipitation amount in EUR-11 $(+80 \%)$ is at least partly attributed to the coarsely resolved orography that leads to an increase of $40 \%$ in setup D compared to the REF simulation. The steeper slopes and higher differences between valleys and hill tops in the $3 \mathrm{~km}$ orography may initialize stronger vertical wind speeds and lift air more easily to the levels of condensation and free convection, which would suggest overall less convective precipitation with coarser orography, contrary to our results where the smoothed orography seems to facilitate the initiation and evolution of more organized and overall larger convective cells that last longer.
This reasoning is also consistent with the higher mean CAPE values observed for the simulations with smooth orography. However, differences to previous studies may also result from different model setups and the simulated season.

Besides local inevitable effects on near-surface variables caused by differing land use types, the reduction of heterogeneity in coarsely resolved land use distributions, going from $3 \mathrm{~km}$ to $12 \mathrm{~km}$ resolution, does not systematically affect the atmospheric flow, temperature or precipitation patterns. However, domain average differences in latent heat flux (about $+3 \%$ between setup $\mathrm{C}$ and REF) and consequently differences in mean cloudiness and precipitation (about $+3 \%$ ) may result from the slightly changing the percentages of land use types upon aggregation. No clear differences in the spatial distribution of hourly precipitation intensities and the mean diurnal cycle are, however, observed between the different setups (not shown). Positive spatial correlations between precipitation and shortwave radiation difference patterns of setups with coarse land use also suggest a nonrandom effect on cloud formation. However, additional perturbed ensemble simulations with each setup and an extension to several summer seasons would be necessary to better assess systematic influences on these difference patterns.

The initial soil moisture distribution more strongly alters the regional-scale atmospheric patterns compared to the scale of the land use type heterogeneity. In our setup, the overall higher (+2.3\% domain average) initial soil moisture taken from transient EUR-11 climate runs (setup A and B) (a)

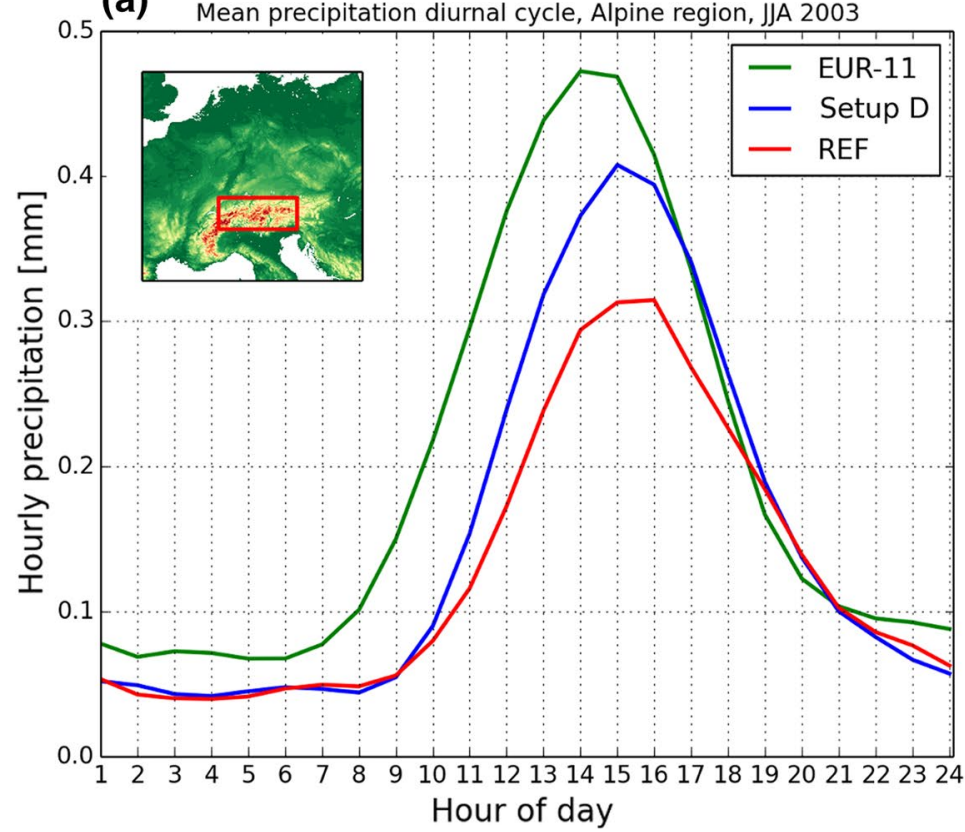

(b)

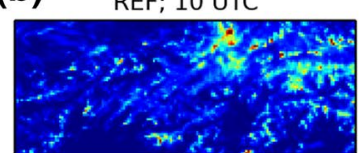

(d)

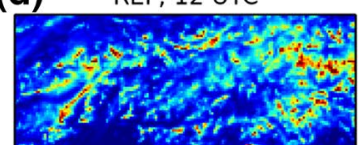

(f)

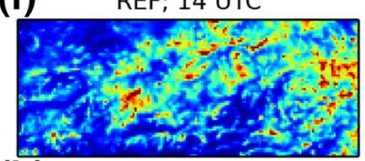

(h)

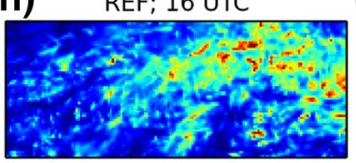

(i) Setup D; 16 UTC

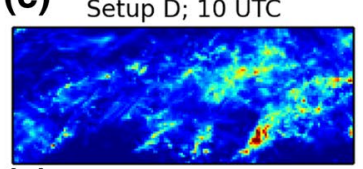

(e) Setup D; 12 UTC

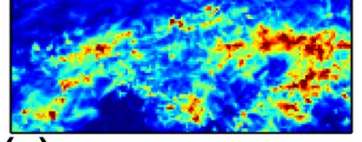

(g) Setup D; 14 UTC
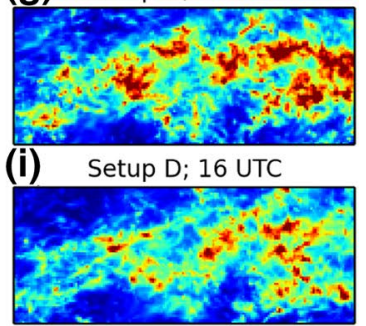

$\begin{array}{llllllllllll}0.0 & 0.1 & 0.2 & 0.3 & 0.4 & 0.5 & 0.6 & 0.7 & 0.8 & 0.9 & 1.0\end{array}$ Hourly precipitation [mm]
Fig. 11 Mean diurnal cycle of precipitation in the Alpine region (for definition see red box in inset in the upper left corner) in setup D and REF as well as in the driving EUR-11 simulation (a) and spatial dis- tribution of summer (JJA) 2003 mean hourly precipitation at 10, 12, 14 and 16 UTC in REF (b, d, f, h) and setup D (c, e, g, i) 
compared to the $3 \mathrm{kmME}$ climate runs (setups REF, C, and D) leads to systematic differences in domain-averaged latent and sensible heat flux and consequently also in cloudiness and precipitation in the order of $6-8 \%$ domain average. The impact of soil moisture differences clearly depends on the preceding weather conditions and is largest for transitions from energy to soil moisture-limited land-atmosphere coupling regimes, that widely occurred during the simulated summer season. In line with previous studies, our results highlight the sensitivity of land-atmosphere coupling to soil moisture dynamics in particular for this anomalous dry summer 2003 (Fischer et al. 2007; Seneviratne et al. 2010; Keune et al. 2016; Knist et al. 2017) and confirms a contrasting response of different land use types (e.g., crop and forest) to heat wave conditions (Teuling et al. 2010).

In summary, when decreasing the spatial resolution of individual land surface properties, orography has the largest impact on the overall simulation results as it alters the flow over and around mountain ridges and largely influences the local precipitation pattern and intensity over regions with complex orography. The effect of a coarser-resolved land use distribution is overall smaller and mainly related to changes in the overall percentages of the different land use types, rather than to the loss of heterogeneity in the surface pattern on the scale analyzed here. But even small changes in soil moisture (both spatial averages and local differences) have a higher potential to affect the overall simulation results, although this might also depend on the particular land surface model used, the treatment of subsurface processes and the investigated season. Overall, differences caused by coarsely resolved land surface properties are much smaller compared to differences between simulations with $3 \mathrm{~km}$ and $12 \mathrm{~km}$ grid spacings of the atmosphere (e.g., Ban et al. 2014; Kendon et al. 2012; Knist et al. 2018; Prein et al. 2013).

Acknowledgements The authors gratefully acknowledge the computing time granted by the JARA-HPC Vergabegremium and VSR commission on the supercomputer JURECA at Forschungszentrum Jülich. Work has been sponsored by the CRC/TR32 project "Patterns in SoilVegetation-Atmosphere Systems: Monitoring, Modelling and Data Assimilation" funded by the German Research Foundation (DFG), through a research and development cooperation on hydrometeorology between the Federal Institute of Hydrology, Koblenz, Germany, and the Meteorological Institute, University of Bonn, Bonn, Germany and through the EC-funded project eLTER H2020 (GA: 654359 - H2020 INFRAIA call 2014-2015). The ERA-Interim data were accessed from http://apps.ecmwf.int/datasets/. The analysis results and the underlying RCM data are available upon request (sebastian.knist@gmx.de). The data are archived at the Jülich Supercomputing Centre, Research Centre Jülich, Jülich, Germany.

Open Access This article is distributed under the terms of the Creative Commons Attribution 4.0 International License (http://creativeco mmons.org/licenses/by/4.0/), which permits unrestricted use, distribution, and reproduction in any medium, provided you give appropriate credit to the original author(s) and the source, provide a link to the Creative Commons license, and indicate if changes were made.

\section{References}

Adler B, Kalthoff N, Gantner L (2011) The impact of soil moisture inhomogeneities on the modification of a mesoscale convective system: an idealised model study. Atmos Res 101:354-372. https://doi.org/10.1016/j.atmosres.2011.03.013

Avissar R, Schmidt T (1998) An evaluation of the scale at which ground-surface heat flux patchiness affects the convective boundary layer using large-eddy simulations. J Atmos Sci 55:2666-2689. https://doi.org/10.1175/15200469(1998)055\%3c2666:AEOTSA\%3e2.0.CO;2

Ban N, Schmidli J, Schaer C (2014) Evaluation of the convectionresolving regional climate modeling approach in decade-long simulations. J Geophys Res Atmos 119:7889-7907. https://doi. org/10.1002/2014JD021478

Barros AP, Lettenmaier DP (1994) Dynamic modeling of orographically induced precipitation. Rev Geophys 32:265. https://doi. org/10.1029/94RG00625

Brunsell NA, Mechem DB, Anderson MC (2011) Surface heterogeneity impacts on boundary layer dynamics via energy balance partitioning. Atmos Chem Phys 11:3403-3416. https://doi. org/10.5194/acp-11-3403-2011

Colle BA, Wolfe JB, Steenburgh WJ et al (2005) High-resolution simulations and microphysical validation of an orographic precipitation event over the wasatch mountains during IPEX IOP3. Mon Weather Rev 133:2947-2971. https://doi.org/10.1175/ MWR3017.1

Di Luca A, de Elía R, Laprise R (2012) Potential for added value in precipitation simulated by high-resolution nested regional climate models and observations. Clim Dyn 38:1229-1247. https ://doi.org/10.1007/s00382-011-1068-3

Di Luca A, de Elía R, Laprise R (2013) Potential for added value in temperature simulated by high-resolution nested RCMs in present climate and in the climate change signal. Clim Dyn 40:443-464. https://doi.org/10.1007/s00382-012-1384-2

Ek MB, Mitchell KE, Lin Y et al (2003) Implementation of Noah land surface model advances in the National Centers for Environmental Prediction operational mesoscale Eta model. J Geophys Res Atmos. https://doi.org/10.1029/2002jd003296

Fischer EM, Seneviratne SI, Vidale PL et al (2007) Soil Moistureatmosphere interactions during the 2003 European Summer Heat Wave. J Clim 20:5081-5099. https://doi.org/10.1175/ JCLI4288.1

Froidevaux P, Schlemmer L, Schmidli J et al (2014) Influence of the background wind on the local soil moisture-precipitation feedback. J Atmos Sci 71:782-799. https://doi.org/10.1175/ JAS-D-13-0180.1

Garcia-Carreras L, Parker DJ, Marsham JH (2011) What is the mechanism for the modification of convective cloud distributions by land surface-induced flows? J Atmos Sci 68:619-634. https://doi. org/10.1175/2010JAS3604.1

Giorgi F, Avissar R (1997) Representation of heterogeneity effects in earth system modeling: experience from land surface modeling. Rev Geophys 35:413-437. https://doi.org/10.1029/97RG01754

Grell GA, Dévényi D (2002) A generalized approach to parameterizing convection combining ensemble and data assimilation techniques. Geophys Res Lett 29:38. https://doi.org/10.1029/2002g1015311

Guillod BP, Orlowsky B, Miralles D et al (2013) Land surface controls on afternoon precipitation diagnosed from observational data: uncertainties, confounding factors and the possible role of vegetation interception. Atmos Chem Phys Discuss 13:29137-29201. https://doi.org/10.5194/acpd-13-29137-2013

Hohenegger C, Brockhaus P, Bretherton CS, Schär C (2009) the soil moisture-precipitation feedback in simulations with explicit and 
parameterized convection. J Clim 22:5003-5020. https://doi. org/10.1175/2009JCLI2604.1

Hong S-Y, Dudhia J, Chen S-H (2004) A revised approach to ice microphysical processes for the bulk parameterization of clouds and precipitation. Mon Weather Rev 132:103-120. https://doi.org/10.1175/1520-0493(2004)132\%3c0103:ARATI $\mathrm{M} \% 3 \mathrm{e} 2.0 . \mathrm{CO} ; 2$

Hong SY, Noh Y, Dudhia J (2006) A new vertical diffusion package with an explicit treatment of entrainment processes. Mon Weather Rev 134(9):2318-2341

Huang H-Y, Margulis SA (2013) Impact of soil moisture heterogeneity length scale and gradients on daytime coupled land-cloudy boundary layer interactions. Hydrol Process 27:1988-2003. https://doi. org/10.1002/hyp.9351

Iacono MJ, Delamere JS, Mlawer EJ et al (2008) Radiative forcing by long-lived greenhouse gases: calculations with the AER radiative transfer models. J Geophys Res Atmos 113:2-9. https://doi. org/10.1029/2008JD009944

Kendon EJ, Roberts NM, Senior CA, Roberts MJ (2012) Realism of rainfall in a very high-resolution regional climate model. J Clim 25:5791-5806. https://doi.org/10.1175/JCLI-D-11-00562.1

Keune J, Gasper F, Goergen K et al (2016) Studying the influence of groundwater representations on land surface-atmosphere feedbacks during the European heat wave in 2003. J Geophys Res Atmos 121:301-325. https://doi.org/10.1002/2016JD025426

Knist S, Goergen K, Buonomo E et al (2017) Land-atmosphere coupling in EURO-CORDEX evaluation experiments. J Geophys Res Atmos. https://doi.org/10.1002/2016jd025476

Knist S, Goergen K, Simmer C (2018) Evaluation and projected changes of precipitation statistics in convection-permitting WRF climate simulations over Central Europe. Clim Dyn. https://doi. org/10.1007/s00382-018-4147-x

Kotlarski S, Keuler K, Christensen OB et al (2014) Regional climate modeling on European scales: a joint standard evaluation of the EURO-CORDEX RCM ensemble. Geosci Model Dev Discuss 7:217-293. https://doi.org/10.5194/gmdd-7-217-2014

Leung LRL, Qian Y, Northwest P (2003) The sensitivity of precipitation and snowpack simulations to model resolution via nesting in regions of complex terrain. J Hydrometeorol 4:1025-1043. https://doi.org/10.1175/1525-7541(2003)004\%3c1025:TSOPA $\mathrm{S} \% 3 \mathrm{e} 2.0 . \mathrm{CO} ; 2$

Nikulin G, Kjellström E, Hansson U et al (2011) Evaluation and future projections of temperature, precipitation and wind extremes over Europe in an ensemble of regional climate simulations. Tellus Ser A Dyn Meteorol Oceanogr 63:41-55. https://doi.org/10.111 1/j.1600-0870.2010.00466.x

Patton EG, Sullivan PP, Moeng C (2004) The influence of idealized heterogeneity on convective planetary boundary layers coupled to the land surface. Ncar. https://doi.org/10.1175/jas3465.1

Pedemonte L, Corazza M, Sacchetti D et al (2005) Verification of limited-area models precipitation forecasts during the MAP-SOP. Hrvat Meteoroloski Cas 40(40):268-271

Prein AF, Gobiet A, Suklitsch M et al (2013) Added value of convection permitting seasonal simulations. Clim Dyn 41:2655-2677. https://doi.org/10.1007/s00382-013-1744-6

Prein AF, Langhans W, Fosser G et al (2015) A review on regional convection-permitting climate modeling: demonstrations, prospects, and challenges. Rev Geophys 53:323-361. https://doi. org/10.1002/2014RG000475
Prein AF, Gobiet A, Truhetz $\mathrm{H}$ et al (2016) Precipitation in the EUROCORDEX $0.11^{\circ}$ and $0.44^{\circ}$ simulations: high resolution, high benefits? Clim Dyn 46:383-412. https://doi.org/10.1007/s0038 2-015-2589-y

Raasch S, Harbusch G (2001) An analysis of secondary circulations and their effects caused by small-scale surface inhomogeneities using large-eddy simulation. Boundary-Layer Meteorol 101:3159. https://doi.org/10.1023/A:1019297504109

Richard E, Buzzi A, Zaengl G (2007) Quantitative precipitation forecasting in the Alps: the advances achieved by the Mesoscale Alpine Programme. Q J R Meteorol Soc 133:831-846. https:// doi.org/10.1002/qj.65

Rieck M, Hohenegger C, van Heerwaarden CC (2014) the influence of land surface heterogeneities on cloud size development. Mon Weather Rev 142:3830-3846. https://doi.org/10.1175/MWR-D13-00354.1

Seneviratne SI, Corti T, Davin EL et al (2010) Investigating soil moisture-climate interactions in a changing climate: a review. Earth-Science Rev 99:125-161. https://doi.org/10.1016/j.earsc irev.2010.02.004

Skamarock W, Klemp JB, Dudhia J, et al (2008) A description of the advanced research WRF version 3. NCAR Tech Note. https://doi. org/10.5065/d68s4mvh

Smith RB (1979) The influence of mountains on the atmosphere. Adv Geophys 21:87-230

Smith SA, Vosper SB, Field PR (2015) Sensitivity of orographic precipitation enhancement to horizontal resolution in the operational Met Office Weather forecasts. Meteorol Appl 22:14-24. https:// doi.org/10.1002/met.1352

Taylor CM, Birch CE, Parker DJ et al (2013) Modeling soil moistureprecipitation feedback in the Sahel: importance of spatial scale versus convective parameterization. Geophys Res Lett 40:62136218. https://doi.org/10.1002/2013GL058511

Teuling AJ, Seneviratne SI, Stockli R et al (2010) Contrasting response of European forest and grassland energy exchange to heatwaves. Nat Geosci 3:722-727

Torma C, Giorgi F, Coppola E (2015) Added value of regional climate modeling over areas characterized by complex terrain-precipitation over the Alps. J Geophys Res Atmos 120:3957-3972. https:// doi.org/10.1002/2014jd022781.received

van Heerwaarden CC, Guerau de Arellano JV (2008) relative humidity as an indicator for cloud formation over heterogeneous land surfaces. J Atmos Sci 65:3263-3277. https://doi.org/10.1175/2008J AS2591.1

Wu C-M, Lo M-H, Chen W-T, Lu C-T (2015) The impacts of heterogeneous land surface fluxes on the diurnal cycle precipitation: a framework for improving the GCM representation of land-atmosphere interactions. J Geophys Res Atmos 120:3714-3727. https:// doi.org/10.1002/2014JD023030

Publisher's Note Springer Nature remains neutral with regard to jurisdictional claims in published maps and institutional affiliations. 